\title{
ANTROPOLOGÍA DE LA IDENTIDAD FEMENINA EN LA FILOSOFIA DE EDITH STEIN
}

\section{Anthropology of female identity in the philosophy of Edith Stein}

\author{
Analyda Boluarte Drago \\ Universidad Femenina Sagrado Corazón: analydaboluarted@unife.edu.pe \\ ID ORCID: https://orcid.org/0000-0003-3973-9227
}

\begin{abstract}
RESUMEN
En este artículo, se analiza la concepción de Edith Stein acerca de la mujer, desde la perspectiva de la antropología filosófica, con un enfoque predominantemente fenomenológico. Se presentan sus ideas como un fundamento para la reflexión filosófica contemporánea acerca de la mujer, vista como persona que posee una dignidad incuestionable. Se resalta así mismo la actualidad de sus planteamientos, principalmente lo que Edith Stein denominaba lo "específico femenino".
\end{abstract}

\section{Palabras clave:}

Persona humana, identidad femenina, dignidad humana.

\begin{abstract}
In this paper, Edith Stein's conception of women is analyzed from the perspective of philosophical anthropology, with a predominantly phenomenological approach. Her ideas are presented as a foundation for contemporary philosophical reflection on women, seen as a person who possesses unquestionable dignity. Likewise, the topicality of her approaches is highlighted, mainly what Edith Stein called the "feminine specific".
\end{abstract}

\section{Keywords:}

Human person, female identity, human dignity. 


\section{INTRODUCCIÓN}

Iniciamos las reflexiones desde la mirada de una mujer de gran inteligencia, muy profunda y buscadora de la verdad. Abordar su pensamiento no deja de ser un reto, puesto que nos encontramos ante una mujer que tiene muchas vivencias y experiencias desde su raíz judía, universitaria, pedagoga, psicóloga, filósofa y teóloga, luchadora de vanguardia por los derechos de la mujer; quien más adelante se convertiría al catolicismo y entraría en la Orden del Carmelo.

Podríamos preguntarnos ¿por qué se interroga sobre la mujer y la complementariedad con el hombre? Una respuesta podría ser, porque siempre se interesó por todo lo referente al ser humano. Otra respuesta nos llevaría a focalizarnos en la Alemania de 1930, en donde surgen movimientos juveniles en franca rebelión contra la generación de sus padres. Estas circunstancias le llevaron a presagiar una profunda ruptura espiritual en su país y comprendió que, para afrontar el reto de la transmisión cultural, educativa y social, era necesario resaltar el papel esencial que puede desempeñar la mujer en la sociedad.

La situación coyuntural, unida a las experiencias que tuvo como profesora de un colegio femenino y luego de un instituto científico, le llevaría a insistir en el tema de la educación de las mujeres.

Es una realidad también, que la situación de la mujer de su tiempo le preocupaba mucho y esta inquietud, le llevó a ser portavoz de la emancipación femenina, denunciando el modo como se arrinconaba - en concreto desde la visión de la ideología nazi del momento - a la mujer desde una postura sumisa y sin proyección social.
Es importante resaltar, que antes de convertirse al catolicismo, ya tenía una alta opinión acerca del lugar de la mujer en la sociedad y en el mundo. Con mayor razón, al convertirse al catolicismo, alzó la voz en nombre de las mujeres y sintió la necesidad de construir una reflexión filosófica sobre la especificidad femenina. Asimismo, como fenomenóloga le interesaba clarificar dos interrogantes básicos: "¿Qué somos nosotras? Y ¿qué debemos ser?". (Stein, 1998, p. 83)

Toda su contribución en relación con la identidad femenina, es un gran aporte para profundizar adecuadamente en el ser, deber ser y hacer de la mujer del siglo XXI. Su punto de partida será, analizar la estructura que constituye a todo ser humano y a partir de ahí, proceder a defender y desarrollar cuanto de específico cualifique a la mujer.

\section{Biografía y trayectoria intelectual}

En algunos filósofos es más relevante que en otros la biografía. En el caso de Edith Stein es particularmente significativa, al ser tan rica cada etapa de su vida y su trayectoria intelectual.

Edith Stein (1891-1942) nació en Breslau (Alemania), hoy Wroclaw, ciudad polaca. Era la sétima hija de un matrimonio judío. Vivió en sus primeros años, de sus raíces judías y del nacionalismo prusiano. "El mundo y el tiempo en el que Edith Stein se desenvuelve, en el que se sitúa conscientemente y a la vez analiza, tiene de preferencia un nombre propio: la Alemania de las guerras y entreguerras, convertida por entonces en el epicentro que hará temblar a Europa y parte del mundo". (García, 2014, p. 20)

Educada en un ambiente judío liberal, llegó un momento que las prácticas 
ritualistas en la sinagoga terminaron por no decirle nada y optó por abandonarlas a los quince años, declarándose atea. En el fondo de su corazón, sentía la petición de unas respuestas que vayan en sintonía con sus inquietudes existenciales acerca del sentido de la vida y de la realidad.

Su madre quedó viuda y desde entonces pudo constatar en un ejemplo vivo, la fuerza de las mujeres, puesto que ésta no se amedrentó ante las circunstancias y siguió trabajando para sacar adelante el negocio familiar.

En 1913 la lectura de las Investigaciones Lógicas de Husserl, le abrieron un nuevo panorama y decide trasladarse a Gotinga, con la finalidad de terminar los cursos universitarios siguiendo cursos dictados por Husserl. Prosiguió en la profundización de la fenomenología, al ser Asistente de Husserl, habiendo defendido brillantemente su tesis doctoral sobre la empatía.

Damos un salto en el tiempo y en los sucesos de su vida, para centrarnos en su acercamiento a la fe. Su conversión al catolicismo, siendo un episodio muy importante en su vida, no supuso una ruptura con la formación fenomenológica anterior, sino un enriquecimiento aún mayor. "La conversión al catolicismo no supuso la renuncia a la fenomenología. Cuando en 1936, redacta su obra filosófica Endliches und ewiges Sein (Ser finito y ser eterno) desde la celda carmelitana, recordará que su patria filosófica es la escuela de Husserl y que su lengua materna continúa siendo la de los fenomenólogos". (García, 2014, p. 42)

No podemos dejar de mencionar, que luego de sus reiterados intentos de encontrar un puesto docente en distintas universidades, decide ejercer como profesora de germanística en el Liceo y en la Escuela de Tanta Magdalena de las Dominicas de Spira, de 1922 a 1931. Entre 1928 y 1933 pronuncia conferencias y participa en Congresos de Pedagogía en Alemania, Austria y Suiza. En 1932 se le asigna la Cátedra en el Instituto de Pedagogía de Munster, dando un curso durante el semestre de 1932 1933, sobre la estructura de la persona.

Son de gran relevancia, las distintas conferencias sobre la mujer dadas por Stein, las cuales nos permiten formarnos una idea de su pensamiento sobre el ser y el deber ser la mujer, al resaltar lo específico de la feminidad.

En relación con su trayectoria intelectual, no cabe duda que Stein sigue a su maestro Edmund Husserl, consiguiendo explicar de manera rigurosa y clara el análisis de la persona humana. Ella misma, por modestia, reconoce que no sabe hasta qué punto algunas de las intuiciones que postula son suyas o son de su maestro, llegando a afirmar lo siguiente( 1998): "Con la escuela fenomenológica, es decir, con la escuela de E. Husserl, comparto la idea de que el procedimiento de la filosofía es, por principio, distinto de las ciencias positivas, la idea de que ella tiene a su disposición una función cognoscitiva propia, y la idea de que precisamente por esto le es posible lograr aquello que es necesario para la fundación de las otras ciencias, y que ellas mismas no pueden lograr". (p. 212)

El pensamiento filosófico de Stein, se ve influenciado por la del Aquinate, al ser requerida para traducir al alemán en dos tomos, las Cuestiones sobre la verdad de Santo Tomás de Aquino (1931-1932). Es así como, sin negar su primera etapa como fenomenóloga, desarrolla en 
los años siguientes una metafísica de inspiración tomista, en Potencia y acto (1930 1931) y en su obra principal, Ser finito y Ser eterno (1936).

\section{Visión antropológica en la filosofía de Edith Stein}

Conviene no perder de vista que la autora en estudio se formó en la escuela fenomenológica de Husserl y que, por lo tanto, sus trabajos llevan su impronta. En esta línea afirmará que la persona está dividida en tres partes: cuerpo psique y espíritu. Ella profundizará en este aspecto y a través del método de la fenomenología demuestra cómo los actos que cumple la persona demuestran que estas dimensiones existen (Haya, 2004).

De sus escritos se deriva que la persona no es un "yo puro" solamente, "sino un yo cuya profundidad la constituyen los diferentes niveles que pueden distinguirse. Afirmará también que la razón es constitutiva del hombre afirmando "Razón y libertad son los distintivos esenciales de la persona". (García, 2011, p. 341)

Avanzando en sus reflexiones, Stein afirmará que la especie humana se despliega en dos: hombre y mujer. Nos encontramos frente a dos modos de ser persona, con igual dignidad y por lo tanto con iguales derechos. Cada uno tiene un valor propio que no es anulado en la diferencia, sino que, por el contrario, los lleva a descubrir el carácter complementario de ambos.

Lo que Stein busca no es anular las diferencias, sino por el contrario, potenciar lo específico, lo complementario, la alteridad. En otras palabras, la originalidad de la mujer frente a la originalidad del varón. "Edith Stein señala estar convencida de que la especie "hombre" se articula en dos especies: especie "viril" y especie "mujeril", y que la esencia del hombre, la cual no puede faltar en uno u otro caso, logra expresarse en dos modos diversos". (García Rojo, 1991, p. 386)

Es una realidad, que los varones y las mujeres, aunque compartan todo lo esencial en la común naturaleza humana, tienen a veces, distintas sensibilidades y necesidades: experimentan el mundo de forma diferente, sienten, planean y reaccionan de manera desigual, lo que puede percibir cualquier persona realista. Todas estas afirmaciones, con los avances de la psiquiatría y la neurociencia, han permitido llegar a una mayor precisión. Dice Stein (1998): "La piscología de los últimos decenios se ha ocupado mucho con las diferencias psíquicas entre los sexos; naturalmente, de la experimentación y la estadística no se ha sacado mucho más de lo que enseña la experiencia habitual". (p. 318)

Al afirmar que el hombre y la mujer se distinguen entre sí, no significa discriminación sino todo lo contrario, es resaltar lo específico de cada uno. Un aspecto concreto donde se evidencia la diferencia es en el cuerpo. A través del cuerpo es posible localizar e identificar a las personas. El cuerpo aparece entonces como algo constitutivo de la entidad personal. "La corporeidad es el modo de hacerse presente la persona entera (cuerpo y alma) en el mundo y en el tiempo. Es decir, para la persona humana su modo de vivir es en el cuerpo y a través de su cuerpo. La corporeidad no es un accidente que le sucede a la persona: no podemos pensar en la persona (al menos en esta vida terrena) si no es con su cuerpo". (García Cuadrado, 2010, pp.138-139) 


\section{Lo específico femenino en la antropología de Edith Stein}

Un primer aspecto que se desprende de su visión antropológica, es la igualdad entre varón y mujer. Dos modos de ser persona, dos expresiones de una común humanidad. Se podría exagerar y actuar en contra de la dignidad humana, apelando a un extremado principio de igualdad, en el que se pierde el equilibrio, cuando se confunden igualdad (de dignidad, de derechos y de oportunidades) con disolución de la diversidad. Podemos decir, que nadie está determinado solamente por el sexo: además de ser hombre o mujer, posee disposiciones y aptitudes propias que le confieren caso por caso particulares condiciones para la actividad artística, técnica, científica, social, etc.

Si bien la mujer ha alcanzado el derecho a ser ella misma, a realizarse asumiendo competencias que hace décadas los tenía vedados, y se ha abierto a todas las actividades profesionales y laborales; es importante seguir insistiendo en el reconocimiento de la igualdad y la diferencia entre mujeres y hombres. Somos iguales en dignidad y derechos como personas, y al mismo tiempo somos diferentes. Esa diversidad es riqueza. "Sin duda las mujeres, hoy más que nunca, necesitan tratar de su identidad propia y específica". (Cerrioti, 2018, p. 17)

Stein apostaba por el reconocimiento de la igual dignidad, sin necesidad que la mujer pierda lo genuino de su feminidad; ya que, si se mimetiza con el sexo opuesto, se convierte en un elemento amorfo e inerte. "Desde luego puede decirse que en caso de necesidad toda mujer sana y normal puede ejercer una profesión, y que no existe ninguna profesión que no pueda ser llevada a cabo por ninguna mujer". (Stein, 1998, p. 31)
Intenta con sus planteamientos, resaltar la especificidad de la mujer, pues sólo a partir de ella puede resultar comprensible su valor propio. "Como filósofa y pedagoga declaro que cada persona humana tiene un valor en sí, y por esto tendría que ser lo más normal del mundo que también las chicas aprendieran todo lo que permitiera su capacidad". (Stein, 1998, p.318) La prudente profesora trató de superar el intelectualismo "masculino" completando la educación del entendimiento con una formación moral, de la voluntad, de los sentimientos y afectos.

Encontramos un eco, respecto a la dignidad de todas las personas, en los postulados Kantianos. Immanuel Kant, precursor del Idealismo alemán, destaca el valor de la persona humana como un fin en sí mismo, haciendo un aporte clave a la conceptualización de la dignidad humana al afirmar "Obra de tal modo que uses la humanidad, tanto en tu persona como en la persona de cualquier otro, siempre al mismo tiempo como un fin y nunca solamente como medio". (Kant, I. 1996, p. 44) En este sentido, siempre que se instrumentaliza al otro o se le utiliza para fines propios, se está lesionando su dignidad como persona.

Una visión reduccionista de la persona, puede de alguna manera encasillar a la mujer en prototipos, apartándose de la real dignidad ontológica del ser personal. Esta posición se puede evidenciar en unas afirmaciones de Hegel, filósofo del Idealismo alemán, el último de la Modernidad, quien se aparta de su predecesor afirmando algo que en pleno siglo XXI puede resultar hasta ofensivo: "El varón representa la objetividad y universalidad del conocimiento, mientras que la mujer encarna la subjetividad y la individualidad, dominada por el 
sentimiento. Por ello, en las relaciones con el mundo exterior, el primero supone la fuerza y la actividad, y la segunda, la debilidad y la pasividad. De ahí que el varón deba alcanzar su realidad en el servicio de las tres actividades sociales hegemónicas: ciencia, Estado y economía..." (Ballesteros, 2000, p. 128)

Encontramos en palabras de Stein un referente que permite ver en los dos modos de ser persona - varón y mujeruna igual dignidad e incluso una dotación de capacidades que irían en dirección contraria a lo que afirma Hegel: "En la capacidad de adaptación está incluida la dotación con los mismos dones que le son propios al hombre, y la posibilidad de realizar el mismo trabajo que él, junto con él o en su lugar". (Stein, 1998, p. 101)

No podemos perder de vista, que la idea de dignidad humana encuentra su fundamentación teórica y su inviolabilidad en una ontología metafísica, es decir en una filosofía del absoluto. La dignidad no se construye ni se otorga, es propia del ser humano. "No es casualidad que tanto Nietzsche como Marx hayan caracterizado la dignidad sólo como algo que debe ser construido y no como algo que debe ser respetado". (Spaemann, 1989, p. 122)

En Edith Stein se excluye tanto el revanchismo como la pasividad. Lo que la mujer ha de ser no lo ha de conseguir en virtud de concesiones de los tiempos modernos, sino por exigencias del despliegue de la naturaleza propia del ser femenino; no será por comparación con el varón, sino prestando atención a su propia identidad.

No queda ninguna duda, que es cada vez más imperiosa la necesidad de mejorar la adecuada percepción antropológica de la mujer, de modo que se valore lo que puede ofrecer al mundo. En este sentido, es comprensible el malestar que manifestaba cuando escuchaba comentarios peyorativos o discriminatorios con respecto a la mujer. "Protestó con energía contra un dicho frecuentemente citado en su época, que consideraba la formación intelectual de la mujer oportuna solamente con vistas al varón, para que los maridos se aburrieran un poco menos con sus esposas. Para Edith, esta actitud resultaba insoportable". (cfr. Stein, 1998, p. 19)

Resaltando algo propio de la mujer, Stein consideraba que además de las estructuras corpóreas diversas del varón y de la mujer; la mujer tiene una unidad de toda la personalidad corpóreoanímica y su alma vive y está presente con mayor fuerza en todas las partes de su cuerpo. Lo afirmará de la siguiente manera (1998): "Me parece que el alma de la mujer vive y está presenta con mayor fuerza en todas las partes del cuerpo, y que en consecuencia queda afectada interiormente por todo aquello que le ocurre al cuerpo, mientras que en el hombre tiene más fuertemente el carácter de instrumento que le sirve en su actuación, lo cual conlleva un cierto distanciamiento consigo mismo". (p. 94)

Su visión antropológica que conduce a la mujer hacia su propia identidad femenina, puede ser que se oponga a una visión reduccionista de la mujer. Por el contrario, la aceptación de la mujer en su propia manera de ser, en su ser único e irrepetible, permitirá su verdadera promoción y liberación de prejuicios o estereotipos limitantes.

Es una realidad, que todos tenemos defectos y probablemente todos nos avergonzamos de los errores que 
podemos haber cometido en el pasado. Edith incide que las mujeres pueden abordar estos sentimientos casi como lo haría una madre, viendo los defectos no como un rasgo aislado que criticar implacablemente ni como una forma de definir toda una vida, sino que pueden seguir un mejor camino. "Ellas ven a las personas como un todo, como un trabajo en proceso y capaces de ser educadas en la grandeza". (Stein, 1998, 105)

Una vez que hemos reconocido junto con Stein la igualdad entre varón y mujer, consecuentemente su idéntica dignidad; destacamos la especial aportación social de la mujer, íntimamente ligada al desarrollo de su femineidad la que tiene como recurso significativo la posibilidad de ser madre. "A la parte "materna" en positivo se refiere, en cambio, la capacidad de la mujer de aceptar y cuidar las relaciones, sin sentirse abrumada por los vínculos y por la generosidad que requieren. Aquí se incluye la capacidad femenina de cuidar de los demás, su sensibilidad ante la necesidad, la creatividad con que sabe nutrir con afecto a las personas que ama". (Ceriotti, 2018, p. 33)

Para la filósofa, hay aspectos propios que la mujer entrega para el desarrollo humano. Reconoce que en la mujer se da de modo particular la facultad sensitiva de proteger y cuidar lo que está en desarrollo. En concreto, podríamos precisar que las mujeres dan vida y nutren naturalmente; amar, proteger, nutrir y educar son deseos naturales y maternales. "La tarea de acoger en sí a un ser vivo en formación y crecimiento, de protegerlo y alimentarlo, exige una cierta clausura en sí misma, y el misterioso proceso de formación de un nuevo ser en el organismo materno es una unidad tan íntima de lo anímico y de lo corporal, que se comprende bien que esta unidad pertenece a la especificidad de la naturaleza femenina en general". (Stein, 1998, p. 94)

Respecto a los dos modos de ser persona, podemos incidir en que la condición sexuada, por un lado, tiene un significado más profundo que el de colaborar en la transmisión de la vida y en el caso de la mujer, la sexualidad marca su personalidad y le posibilita una cierta donación de sí misma, necesaria para la familia y para la sociedad. En este sentido podemos afirmar, que el hombre y la mujer, no se distinguen por sus cualidades intelectuales o morales, pero sí en un aspecto mucho más fundamental y ontológico: en la posibilidad de ser padre o madre.

Edith nunca dudó que ser madre es una vocación irremplazable a la que muchas mujeres están llamadas. No todas las mujeres necesitan ser madres - ella misma no lo fue- para llevar vidas felices y plenas, pero solo una mujer puede ser llamada a serlo. Se necesita de la mujer, quitando todo rastro que infravalore esta vocación, de modo que la verdadera condición femenina se exprese en la capacidad de hacer "hogar", no sólo en la propia familia, sino también en la empresa u oficina donde trabaje. "El mundo tiene una gran necesidad de las mujeres, de su modo de ver las cosas, de amar y cultivar la belleza junto a la utilidad, de hacerse cargo de todo lo que necesita cuidado". (Ceriotti, 2018, p. 16)

Stein parte de una realidad objetiva, al sostener que la maternidad no es solamente un proceso fisiológico. Es sobre todo un acontecimiento que interpela a la mujer en su más íntima raíz y corresponde a la estructura psico-física de su feminidad. 
Con miras a una significativa valoración de la maternidad, como algo específico de la mujer podemos reflexionar en torno a las siguientes palabras: "La progresiva desaparición de lo maternal lleva consigo la desaparición de la actitud concreta hacia la realidad humana que comporta la buena cultura materna. Es una actitud de acogida, compasión, de atención a la necesidad, de protección y cuidado. Su desaparición arrastra aquella dramática disminución del valor de la vida y de la persona, que está a la vista de todos nosotros". (Ceriotti, 2018, p. 56)

Es una realidad, que la conciliación familia y trabajo, maternidad y paternidad es algo a conseguir. Asimismo, es una tarea pendiente de la misma sociedad, el revisar las estructuras laborales desde una clave antropológica y ética, no tan sólo económica.

\section{CONCLUSIONES}

A modo de conclusión, podríamos decir que en sus escritos Edith Stein habla no sólo a las mujeres, sino a toda la humanidad. Es muy clara al detallar lo específico femenino, sin ánimo de adoptar una postura antagónica con respecto al varón.

Lo que precisa con respecto a los dos modos de ser persona - varón y mujer - se ubica más allá de simples discursos ideológicos, sean progresistas o conservadores; lo que busca como lo hizo a lo largo de su vida, es buscar la verdad. Esa verdad se encuentra no al eliminar las diferencias entre hombre y mujer, sino al resaltar y potenciar las diferencias. En este sentido, no hace falta que la mujer se enfrente con el hombre o intente imitarlo, puesto que esta actitud podría desvirtuar la esencia femenina radical.
Asimismo, sus planteamientos van en la línea de afirmar una igual dignidad entre el hombre y la mujer; por lo tanto, igualdad de derechos y oportunidades. Hace falta también, que la misma mujer sea consciente de sus derechos como ciudadana, esposa, madre y se empodere en base a lo propio que aporta a la sociedad; no dejándose llevar por ninguna manipulación abierta u oculta.

Queda claro, que los estereotipos, a pesar de los tiempos convulsos en los que le tocó vivir, no son válidos y sus planteamientos vanguardistas para la época, se hacen cada vez más evidentes en pleno siglo XXI con los avances psicológicos, neurológicos y de la ciencia en general.

Stein apuesta por la mujer y por la mejora de su situación en el ámbito educativo, laboral y social. Su voz en la actualidad, le reclamaría a la mujer la valentía para no tener miedo a afirmar lo propio de su identidad femenina -puesto que la diversidad de por sí es riqueza- y a no sucumbir en discursos ideológicos que proponen la anulación de las diferencias, a costa de una igualdad mal entendida.

\section{REFERENCIAS}

Balmaseda, C. (1984). La mujer frente a sí misma. Eunsa.

Ballesteros, Jesús. (2000). Postmodernidad: Decadencia o resistencia. Tecnos.

Burggraf, Jutta. ( 2011 ) Varón y mujer: ¿naturaleza o cultura? Altar Mayor, $N^{\circ}$. 139. pp 179-192 https://dialnet.unirioja.es/servlet/ articulo?codigo $=3412975$ 
Ceriotti Migliarese, Mariolina. (2018). Erótica y materna. Un viaje al universo femenino. Rialp

Chesterton, G. (2006). La mujer y la familia. Styria.

Eguíbar, M. (2003). La nueva identidad femenina. Palabra.

García Cuadrado, José Ángel. ( 2010 ). Antropología Filosófica. Una introducción a la Filosofía del Hombre. Eunsa.

García Rojo, Ezequiel. (1991). Edith Stein y el tema de la mujer. Revista de Espiritualidad, n 50. http://www. revistadeespiritualidad.com/upload/ pdf/2228articulo.pdf

García Rojo Ezequiel. (1999). La mujer de Edith Stein. Monte Carmelo: Revista de Estudios Carmelitanos, ISSN 0544-9073, Vol. 107, No. 2-3, pp. 433-453. https://dialnet.unirioja. es/servlet/autor?codigo $=290491$

García Rojo Ezequiel. (2011). El cuerpo: puente hacia el otro en Edith Stein. Revista de Espirtualidad $n^{\circ}$ 280. https://dialnet.unirioja.es/ servlet/autor?codigo $=290491$

García Rojo Ezequiel. (2014). El siglo XX a la luz de Edith Stein. Revista de Espiritualidad n²92. https://dialnet.unirioja.es/servlet/ autor?codigo $=290491$

Haaland, J. (2000). El tiempo de las mujeres. Rialp.

Haya Segovia, Fernando. (1997). La fenomenología metafísica de Edith Stein: una glosa a "ser finito" y "ser eterno". Cuadernos de Anuario Filosófico.
Serie Universitaria, $n^{\circ}$ 46. Url: https://hdl.handle.net/10171/6357.

Haya Segovia. Fernando. (2004). La estructura de la persona humana según Edith Stein. Cuadernos de Anuario Filosófico. Serie Universitaria 151 200: Servicio de Publicaciones de la Universidad de Navarra. Url: https:// hdl.handle.net/10171/4083

Kant, Immanuel. (1996). Fundamentación de la metafísica de las costumbres. Porrúa.

Macintyre, A. (2001). Animales racionales $y$ dependientes. Por qué los seres humanos necesitamos las virtudes. Paidós.

Macintyre, Alasdair. (2008). Edith Stein. Un prólogo filosófico. Publicaciones del Instituto de Filosofía "Edith Stein". Editorial Nuevo Inicio, 327. https://revistas. unav.edu/index.php/persona-yderecho/article/view/32336

Salinas Alonso, F. (2014). La mujer visible. Feminismo para el siglo XXI. Palabra.

Salvarini, F. (2012). Edith Stein. Hija de Israel y de la Iglesia. Palabra.

Spaemann, R. (1989). Lo natural y lo racional. Rialp

Stein, E. (1998). La mujer. Su papel según la naturaleza y la gracia. Palabra.

Fecha de recepción: 20-08-2020

Fecha de aceptación: 25-10-2020 